ARTIGO TEMA LIVRE

\title{
Considerações para uma ontogênese da política pelo trabalho
}

\section{Jaime Hillesheim}

Universidade Federal de Santa Catarina (UFSC)

\author{
Giovanny Simon Machado \\ Universidade Federal de Santa Catarina (UFSC)
}

\section{Considerações para uma ontogênese da política pelo trabalho}

Resumo: O presente artigo tem como objetivo a elaboração de considerações introdutórias para o entendimento da política com sua origem mediante a categoria trabalho, entendido na obra dos pensadores Karl Marx e György Lukács como mediação fundamental entre humanidade e natureza, produtor de valores de uso e momento fundante do ser social. Realizada pesquisa bibliográfica, sistematizando as principais categorias marxiano-lukacsianas e relacionando-as com a política. Como ontogênese, auferiu-se que o surgimento da política está vinculado ao trabalho, pois mimetiza as suas operações fundamentais. O trabalho como pôr teleológico primário é ação consciente que, por meio da prévia-ideação, planeja a execução e movimenta legalidades da matéria criando objetos úteis para seus fins. Por seu turno, os pores secundários, dentre os quais destaca-se a política, ainda que derivados do trabalho, dele se distinguem e incidem sobre indivíduos na realização de seus pores concretos. O surgimento da política, assim, está relacionado à necessidade do convencimento, ou da tentativa de induzir homens ou grupos de homens a realizarem determinadas atividades dentro de uma forma específica de sociabilidade.

Palavras-chave: Ontologia. Trabalho. Política.

\section{Considerations for an Ontogenesis of Labor Policy}

Abstract: The objective of this article is to develop introductory considerations for an understanding of politics whose origin is seen through the category of labor. In the work of Karl Marx and György Lukacs labor is understood as the fundamental mediation between humanity and nature, the producer of use values and a foundational moment of the social being. Bibliographic research was conducted, systematizing the main Marxian-Lukacsian categories and relate them to politics. As ontogenesis, it was recognized that the rise of politics is linked to work, because it mimics its fundamental operations. Labor, for primary teleology, is conscious action that by means of previous ideation, plans the execution and moves legalities of matter creating objects that are useful to its goals. In turn, the secondary pores, among which politics is highlighted, even if derived from labor, are distinct from it and influence individuals in the realization of their concrete pores. The rise of politics is thus related to the need for persuasion, or to the attempt to induce men or groups of men to conduct certain activities within a specific form of sociability.

Keywords: Ontology. Labor. Politics. 


\section{Introdução}

Pretendemos, nesse artigo, lançar considerações para a compreensão da política como práxis que possui uma vinculação ontogenética com o desenvolvimento do ser social, cuja origem está demarcada na atividade do trabalho. E, quando nos referimos à expressão "ontogenética", buscamos recuperar a base histórico-material de gênese da política como atividade especificamente humana. Tal reflexão ampara-se nas contribuições de Karl Marx - especialmente em sua obra O Capital, e os escritos de Para a Questão Judaica - e György Lukács - em sua Ontologia do Ser Social.

Considerando os limites objetivos com os quais temos de lidar para desenvolver nossas reflexões, parece-nos salutar esclarecer que o que nos interessa, aqui, é situar a relação entre o trabalho e a política, de maneira a identificar como e por que o trabalho torna-se um modelo de práxis social, e mais especificamente no âmbito da política, como ela também adere, e de que forma, a algumas das operações e características próprias do trabalho. Nesse sentido, quando falamos do trabalho, estamos tratando do espectro geral, não necessariamente o trabalho em algum tipo de sociedade específica, mas sim dele como relação ineliminável de mediação entre o homem e a natureza, nos exatos termos expressos por Marx (2013) e Lukács (2013). Na esteira dos fundamentos dessa tradição teórica, é importante lembrar que, no processo de complexificação do ser social, distintas formas de trabalho e de produção resultam em formas particulares de práxis sociais, dentre as quais peculiares formas de política.

Para desenvolvermos esse debate, organizamos o artigo em duas partes que se articulam entre si. Na primeira, centramos nossa análise nos principais argumentos dos autores supracitados com relação à categoria trabalho, entendida como posição teleológica originária do ser social, e por meio da qual esse ser é capaz de apropriar-se idealmente da realidade das cadeias causais nela atuantes e estabelecer uma finalidade com vistas a responder determinadas necessidades. Nesse processo pelo qual se engendra o desenvolvimento do ser, novas necessidades e possibilidades são reiteradamente geradas, requerendo respostas que podem não ser dadas por meio da atividade do trabalho, mas por outros diferentes pores teleológicos que caracterizam práxis puramente sociais. É aí que situamos a política com uma dessas práxis que ganha objetividade e autonomiza-se, ainda que de modo relativo, daquele complexo originário. Em seguida, passamos a discorrer sobre o caráter ontonegativo da política, enfatizando, com base nos pressupostos teóricos marxiano-lukacsianos, que o ser social não é um ser político por natureza. Além disso, seu desenvolvimento não está condicionado aos esforços que é capaz de envidar para qualificar ou aperfeiçoar esse pôr teleológico parcial, haja vista que autoimplicado no movimento dinâmico e na estrutura da sociabilidade regida pelo capital - forma mais diversificada e complexa do ser que engendra a própria política. Por fim, apresentamos algumas considerações sobre a práxis política, enfatizando que ela exige a apreensão da realidade a partir de uma perspectiva ontológica, condição sine qua non para que não se caia num voluntarismo ou num pragmatismo politicista sem força para transformar a própria realidade. E, nesse diapasão, destacamos que a política deve ser concebida, do ponto de vista dos trabalhadores, como uma mediação para a construção de uma nova sociabilidade.

\section{A gênese e o desenvolvimento do ser social pelo e no trabalho}

O trabalho, como atividade pela qual se produz valor de uso, é uma atividade indispensável para a humanidade em qualquer forma particular de sociedade. Como primeira atividade especificamente humana, o trabalho compreende o processo de prévia-ideação e escolha entre alternativas concretas: o ser humano, antes de realizar o seu trabalho, elabora idealmente seu objetivo e escolhe a melhor alternativa para materializar aquilo que ainda é apenas uma ideia. Essa operação ontológica originará outros pores, como a linguagem, a ciência, a arte, o direito, a política, etc., que têm no trabalho uma práxis modelo. Aos poucos, esses outros pores também assumirão alguma autonomia, ainda que nunca completa, do trabalho.

De acordo com os fundamentos marxianos reafirmados por Lukács (2013), a substância particular do ser social, na produção e reprodução do seu ser, é o trabalho. O trabalho é a mediação ineliminável entre o homem e a natureza, sendo certo que o primeiro não está em oposição à segunda, pois dela é parte constitutiva.

O trabalho humano, desde uma perspectiva ontológica, consiste numa atividade orientada a um fim, é sempre realizado no sentido de sanar uma necessidade do ser humano. Esse atendimento da necessidade como princípio orientador geral da atividade produtiva precisa ser considerado no exato sentido apontado pelo pensamento marxiano, pois isso não quer dizer que o trabalho

[...] se limite a uma alteração da forma do elemento natural; ele realiza neste último, ao mesmo tempo, seu objetivo, que ele sabe que determina, como lei, o tipo e o modo de sua atividade e ao qual ele tem de 
subordinar sua vontade. E essa subordinação não é um ato isolado. Além do esforço dos órgãos que trabalham, a atividade laboral exige a vontade orientada a um fim, que se manifesta como atenção do trabalhador durante a realização de sua tarefa, e isso tanto mais quanto menos esse trabalho, pelo seu próprio conteúdo e pelo modo de sua execução, atrai o trabalhador, portanto, quanto menos este último usufrui dele como jogo de suas próprias forças físicas e mentais. (MARX, 2013, p. 256).

Marx (2013) enuncia aí uma questão de suma importância para o desenvolvimento ulterior do ser social: a intrínseca relação entre a finalidade do trabalho e o modo como ela é perquirida por essa ação propriamente dita. $\mathrm{O}$ atendimento de necessidades e o trabalho como mediação entre o homem e a natureza para saná-las está em profundo vínculo com as formas históricas específicas e particulares de trabalho, igualmente o trabalho alienado e estranhado na sociedade capitalista.

O atributo de elaborar idealmente o seu objetivo antes da ação destaca a diferença entre o trabalho humano e o trabalho animal como epifenômeno: “[...] [no] final do processo de trabalho, chega-se a um resultado que já estava [inicialmente] presente na representação do trabalhador [...], portanto, um resultado que já existia idealmente" (MARX, 2013, p. 256). Essa é uma característica própria do ser social, pois o comportamento animal é completamente restrito ao espectro de sua reprodução biológica (LUKÁCS, 2013); está correlacionado às suas predisposições genéticas e não a escolha entre alternativas. O ser social, por outro lado, desenvolveu sua capacidade de prévia-ideação e de produção de ferramentas e objetos úteis simultaneamente à selvageria própria do mundo animal. Os processos de desenvolvimento desse ser, por certo, implicaram um longuíssimo percurso histórico, mas que foram sendo construídos e constituídos por transformações hereditárias acumuladas ao longo dos séculos, transmitidos de geração em geração. Há que se destacar, contudo, que houve um salto ontológico que significou uma "[...] ruptura com a continuidade normal do desenvolvimento e não pelo nascimento, de forma súbita e gradativa, no tempo, da nova forma de ser. [O que implicou uma] [...] mudança qualitativa e estrutural [...]" (LUKÁCS, 2013, p. 46), ainda que conservados elementos de sua forma pretérita.

A teleologia é aqui entendida como atividade ideal (prévia-ideação) orientada por uma finalidade, com vistas a atender necessidades, nos termos desenvolvidos por Lukács (2013). Já a causalidade foi definida pelo mesmo autor como uma lei fluida na qual a totalidade dos movimentos de todas as formas de ser encontram sua manifestação ou expressão geral. A causalidade representa uma síntese dos acontecimentos e suas consequências e efeitos. Eventos, inicialmente isolados entre si, podem gerar um efeito, e esse efeito, por sua vez isolado, pode não representar nada, porém, quando ligado a outro, juntos causam um novo efeito qualitativamente diverso, e assim sucessivamente, constituindo uma ordem ou cadeia causal. A dialética entre causalidade e teleologia é descrita assim por Lukács (2013, p. 48):

Vale dizer que, enquanto a causalidade é um princípio de automovimento que repousa sobre si próprio e mantém esse caráter mesmo quando uma cadeia causal tem o seu ponto de partida num ato de consciência, a teleologia, em sua essência, é uma categoria posta: todo processo teleológico implica o pôr de um fim e, portanto, numa consciência que põe fins.

É o ato consciente e cognitivo que separa decisivamente seres humanos da simples reprodução biológica própria dos animais. Mas isso não ocorre por uma epifania que lhe concede o dom do conhecimento, mas apenas pelo trabalho, pelo pôr teleológico, gradativamente e socialmente, que vai desenvolvendo uma consciência humana, conforme demonstra Lukács (2013).

$\mathrm{Na}$ natureza virgem, nada há aprioristicamente dado para as realizações da história humana ${ }^{1}$. Por meio do trabalho, cujo ato divide-se num pôr do fim e na investigação dos meios, põem-se em movimento as propriedades e legalidades internas de objetos ou matérias naturais, permitindo que o ser humano seja capaz de realizar as conexões entre os diversos elementos e produzir coisas totalmente novas. A produção de coisas novas "[...] significa que essa atividade natural se transforma numa atividade posta, sem que mudem em termos ontológico-naturais, os seus fundamentos." (LUKÁCS, 2013, p.55), sendo certo que, aí, as causas naturais continuam operantes.

A matéria natural, objetivamente dada, não emite opinião sobre as coisas, posto que é apenas objeto e não sujeito. Os atos de julgar, avaliar, classificar e apreciar só surgem à medida que surge, pelo trabalho, o pensar a realidade para que se alcancem os fins desejados; são, portanto, objetividades sociais. Então, "[...] a investigação dos meios para realização do pôr do fim não pode deixar de indicar um conhecimento objetivo da gênese causal das objetividades e dos processos cujo andamento pode levar alcançar o fim posto." (LUKÁCS, 2013, p. 54). É o conhecimento objetivo das legalidades e causalidades internas das coisas que contribui para que o ser social seja capaz de pô-las em movimento, alcançando sua finalidade pré-estabelecida. 
Aqui é onde se inaugura, na argumentação de Lukács (2013), um campo fundamental para nossas reflexões sobre a ontogênese da política pelo trabalho. Trata-se do campo da separação entre sujeito e objeto em razão do espelhamento, essencial para pensar-se o pôr teleológico do trabalho. Há dois momentos heterogêneos que constituem o fundamento ontológico dessa atividade: o espelhamento da realidade das cadeias causais e o pôr do fim propriamente dito. O ser social, no processo de trabalho, busca, por um lado, "[...] o espelhamento mais exato possível da realidade considerada e, de outro, o correlato pôr daquelas cadeias causais que, como sabemos, são indispensáveis para realização do pôr teleológico." (LUKÁCS, 2013, p. 64-65). Se o pôr do fim exige um mínimo conhecimento objetivo da realidade para sua efetivação, então isso pressupõe a existência de uma separação entre sujeito e objeto: o sujeito que conhece o objeto de sua intervenção. "Essa separação tornada consciente entre sujeito e objeto é um produto necessário do processo de trabalho e ao mesmo tempo a base para o modo de existência especificamente humano." (LUKÁCS, 2013, p. 65). Na esteira dessas reflexões, Lukács (2013) aponta que é a partir do trabalho, da experimentação, da escolha das alternativas na realização prática, que o homem realiza generalizações para desenvolver conhecimento ${ }^{2}$.

A ontologia pressupõe o conhecimento do ser, mas as ordens causais, ao serem postas pelos pores teleológicos, podem dar resultados imprevisíveis e inesperados depois da ação humana. Isso apenas demonstra que o conhecimento nunca será absoluto, suas legalidades são passíveis de novíssimas descobertas que derrubam os mais firmes axiomas. De acordo com o pensamento de Lukács (2013), mesmo que os indivíduos possam ter algum conhecimento residual do corolário das ações singulares, as conclusões generalistas para o qual afluem formam novas cadeias de causalidades que já não guardam qualquer semelhança com suas finalidades primárias e conscientes. A história permanece sendo governada pela causalidade, mesmo que os indivíduos se considerem em pleno controle de suas ações singulares. Mas o fato intrínseco na proposição marxiana de que os homens fazem sua história, apesar de em última instância o fazerem sob as cadeias causais legadas, é que o ser humano, ao agir, sempre possui não só a possibilidade de investigar os meios e espelhar ou reproduzir idealmente a realidade objetiva, mas ele também tem o poder de escolher qual a melhor alternativa para realizar o pôr do fim. Isso porque "[...] [a] alternativa, que também é um ato de consciência, é, pois, a categoria mediadora com cuja ajuda o espelhamento da realidade se torna veículo do pôr de um ente." (LUKÁCS, 2013, p.73). Ademais, as alternativas, por mais numerosas e complexas que sejam as mediações no seu interior, estão sempre ligadas a circunstâncias concre-

Se, no âmbito da atividade fundante do ser social, a teleologia coloca o desafio de compreender as legalidades naturais para transformar a própria objetividade dada, na política a teleologia deve ser capaz de desvelar a objetividade social para imprimir um conjunto de transformações que se materializam em determinadas formas de pensar e agir no contexto da sociabilidade. tas para o atendimento de necessidades do pôr do fim. Em outras palavras, elas ligam-se ontologicamente ao saciar das necessidades de reprodução da vida; os fins incidem diretamente sobre os meios escolhidos (LUKÁCS, 2013).

As questões delineadas sobre os caminhos da práxis social, em suas diversas formas, ainda que traduzidas aqui de maneira sucinta, permitem-nos apontar algumas ligações entre o trabalho e a política. Importa destacar que, no processo de desenvolvimento do ser, necessidades e possibilidades são constantemente geradas e exigem respostas que nem sempre são dadas por meio do trabalho, mas por outros pores teleológicos que caracterizam práxis puramente sociais.

Nesse sentido, se admitirmos que a política é uma objetividade social porque materialmente posta pela humanidade (mas que se diferencia da posição teleológica primária) como tal, ela pode ou não existir em determinadas formas sociais e pode até mesmo apresentar características muito distintas quando se confrontam períodos históricos. Ademais, é preciso ter presente que, em face dos processos de complexificação social, a política figura como um complexo parcial que ganha objetividade e autonomiza-se, ainda que de modo relativo, do complexo que a ela deu origem. No processo de reprodução do ser social, os complexos que surgem a partir da base material terminam por ter uma dinâmica própria, adquirem autolegalidades que fazem parecer que eles se encontram desconectados do complexo originário. 


\section{O caráter ontonegativo da política}

A política, como práxis social milenar, também constitui um complexo derivado do trabalho, entendido como complexo originário do ser social. Com relação à primeira, contudo, não é possível afirmar que se trata de uma atividade fundante e inerente ao ser social, isso porque ela é própria da divisão da sociedade em classes, e, portanto, no âmbito de pensamento lukacsiano, prescindível para a humanidade, diferentemente do trabalho. O que interessa a Lukács (2013) é mostrar qual a particularidade da política como práxis social, ainda que nesse autor não encontremos uma teoria da política ou do Estado. Opondo-se a uma tradição filosófica (Aristóteles, Rousseau, etc.), Lukács defende a tese de que não é possível pensar a política em termos universais, haja vista que sua compressão está atrelada a sua própria historicidade.

Para assimilarmos essa defesa, é imprescindível termos presente que a capacidade do ser social, legada por seu autodesenvolvimento por meio do trabalho ${ }^{3}$, do pôr teleológico, constituído pelo espelhamento na consciência da realidade das cadeias causais, que busca pôr em movimento legalidades e propriedades das coisas para o atendimento de necessidades, cria uma dimensão nova para a totalidade do ser que antes inexistia: a dimensão do futuro. Projetar previamente a ação que se vai executar no futuro, seja ele breve ou longínquo, aos poucos deu à humanidade a possibilidade de projetar não apenas sua atividade produtiva, mas as mais variadas esferas da vida humana que só podem ser compreendidas adequadamente enquanto analisadas pelo método ontogenético. Lukács (2013, p. 99) define essa mudança qualitativa da seguinte maneira:

O momento determinante imediato de qualquer ação intencionada que vise à realização deve por isso ser já esse dever-ser, uma vez que qualquer passo em direção à realização é determinado verificando se e como favorece a obtenção do fim. O sentido da determinação inverte-se deste modo: na determinidade normal biológica, causal, portanto tanto nos homens quanto nos animais, surge um desdobramento causal no qual é sempre inevitavelmente o passado que determina o presente. [...] O pôr de um fim inverte, como já vimos, esse andamento: o fim vem (na consciência) antes da sua realização e, no processo que orienta cada passo, cada movimento é guiado pelo pôr do fim (pelo futuro).

O dever-ser inerente ao pôr do fim, que está presente na consciência, é que orienta cada passo da realização do objetivo estabelecido. Essa dimensão do futuro ganha especial importância na política, que, como qualquer atividade humana, é também um pôr teleológico. Antever o movimento do adversário político é fundamental para aquele que busca alcançar seus objetivos. Não por acaso, Maquiavel $(2005$, p. 38) identificou isso ao analisar as ações no âmbito do Estado, afirmando que "[...] a antevisão (o que só é dado ao homem prudente) dos males que virão torna possível curá-los facilmente".

Na esteira dessa reflexão, no contexto da práxis política, o delineamento de estratégias para alcançarem-se objetivos ganha destaque. No mundo militar, por exemplo, é comum definir a estratégia no sentido indicado por Harnecker (2012, p. 63), para quem esta é uma

[...] forma de planejar, organizar os diversos elementos (campanhas e operações), tendo em conta uma visão de conjunto de todas as forças das quais se conta, assim como as forças inimigas, para atingir o objetivo fixado: ganhar a guerra contra determinados adversários.

Na política, Harnecker (2012, p. 66) define a estratégia revolucionária como “[...] o caminho geral pelo qual deve ser canalizada a luta de classes do proletariado para conseguir o seu objetivo final [...]”. Há aí também um elemento ligado ao futuro, já que o planejamento sempre invoca a dimensão póstera. É um equívoco, todavia, realizar uma transposição maquinal da dimensão futura presente no trabalho em sua forma geral para o domínio da política. Existem muitas mediações complexificadoras entre a antecipação dos resultados na política e no trabalho que devem ser consideradas. O que afirmamos aqui é uma relação derivada, ou seja, a capacidade humana de antecipar os resultados do trabalho guiada pela ação direcionada a um fim dá origem à capacidade de planejar e premeditar as repercussões da atividade política, que figura uma práxis puramente social, dentre várias outras.

Se o dever-ser é o que orienta a ação até a realização do fim estabelecido, então significa dizer que, em última instância, os fins condicionam os meios. Não os determinam em absoluto, até porque é possível inventar outros meios para atingir o mesmo fim. Todo o trabalho humano, toda técnica e seus instrumentos estão em ligação ontológica com a realização dos fins, todavia, sempre em algum nível de complexidade, já que a complexificação da sociedade produz mediações cada vez mais distantes do fim, entre a ação e o atendimento das necessidades humanas. Mesmo que haja essa determinidade do fim na ação humana, jamais pode ser menosprezado o papel da autonomia que assume a investigação dos meios pelo espelhamento, algo que alhures mencionamos. 
Sempre que os seres humanos procuram capturar a objetividade pelo espelhamento para porem em movimento certas cadeias causais, eles não apenas as reproduzem idealmente, mas o fazem condicionadamente aos fins designados, julgando, portanto, se tal objetividade serve ou não para eles. Isso implica sempre um juízo de valor ${ }^{4}$, um discernimento das coisas úteis e inúteis.

O valor dessa natureza genética do ser social está determinado pela possibilidade de satisfazer os fins ligados à reprodução social. O discernimento do bom e do ruim é herdado por outras formas de práxis social de distintas maneiras: a razão, a ética e a moral vão consubstanciar-se em formas políticas e orientar, em seu julgamento, os indivíduos e seus grupos naquilo que é mais adequado para o cumprimento de suas finalidades, mesmo na ética maquiavélica, em que a manutenção da ordem e do poder nas mãos do príncipe estão acima de tudo.

Ao desenvolver suas ideias a respeito da totalidade do ser, Lukács (2013) reitera a relação existente entre a posição teleológica originária (trabalho) e os chamados pores secundários. Quando a divisão social do trabalho complexifica-se, e o trabalho começa a tornar-se cada vez mais social, alguns homens ou grupos tendem a assumir funções específicas dentro da divisão total que podem liberá-los do trabalho direto de produção de valores de uso. A intensificação da divisão social do trabalho implicou, ao longo do percurso histórico da humanidade, o surgimento de atividades relacionadas, por exemplo, a necessidade do convencimento, ou de tentar induzir homens ou grupos de homens a realizarem determinadas atividades dentro de uma forma específica de sociabilidade:

Nas formas ulteriores e mais desenvolvidas da práxis social, destaca-se em primeiro plano a ação sobre outros homens, cujo objetivo é, em última instância - mas somente em última instância - uma mediação para a produção de valores de uso. [...] [O] conteúdo social do por teleológico nesse momento - falando em termos inteiramente gerais e abstratos - é a tentativa de induzir outra pessoa (ou grupo de pessoas) a realizar, por sua parte, pores teleológicos concretos. (LUKÁCS, 2013, p. 83).

Se, no âmbito da atividade fundante do ser social, a teleologia coloca o desafio de compreender as legalidades naturais para transformar a própria objetividade dada, na política a teleologia deve ser capaz de desvelar a objetividade social para imprimir um conjunto de transformações que se materializam em determinadas formas de pensar e agir no contexto da sociabilidade. Sem alcançarem-se essas transformações na realidade, a rigor, não se tem uma posição política, mas apenas uma vontade ou uma assertiva que não ultrapassa o mero discurso. Portanto, a práxis política exige que sejam apreendidas as conexões da totalidade social - de suas causalidades - para transformá-la. Situa-se, aí, a importância da política como práxis que necessariamente implica uma intervenção na realidade. Situando o debate da política no âmbito da ideologia, Lukács (2013) afirma que esta é uma forma de política, já que, pela primeira, o ser social toma consciência da realidade social e dos conflitos que nela existem (independentemente se baseada em ideias falsas ou verdadeiras) e elabora respostas com vistas a solucioná-los ou enfrentá-los, colocando o próprio ser numa nova e mais complexa condição. Sem garantir que transformações na realidade sejam processadas, as ideologias não passam de simples ideias. A política, nesse sentido, tem um componente essencialmente ideológico na medida em que ela implica uma intervenção sobre a realidade humana, provocando nela transformações.

Os pores secundários tornam-se mais complexos e cada vez mais numerosos e também multíplices, à medida que a socialização aumenta. Abstratamente, a política é um grande exemplo de um pôr secundário: é a atividade própria do convencimento (pela força ou por outros meios) da posição de cada indivíduo ou grupo da sociedade. É o pôr próprio para que outrem realize pores segundo os desígnios de poder e os fins dos primeiros.

Podemos dizer que, ao agir politicamente, o ser humano está agindo orientado por um fim. E, para alcançá-lo, tenta induzir e convencer outros para que ajam conforme sua aspiração, o que envolve valores éticos e a disputa de projetos societários. A causalidade continua governando a matéria de sua intervenção, mas ela possui já uma posição, já é uma causalidade própria que possui vontades, consciência, e pode movimentar-se de maneira completamente impensável ${ }^{5}$.

Na sociedade mais complexificada e de grande socialização, o espectro de alternativa não é determinado pela vontade dos indivíduos, como já afirmamos, pois todas as ações e alternativas estão condicionadas pelas circunstâncias presentes. É com esse presente que o agir humano pode procurar um futuro, mas sempre ligado e condicionado por esse presente legado. Cada resposta, entretanto, também está orientada por fins determinados e contém então um valor, haja vista que

Os homens respondem - mais ou menos conscientemente, mais ou menos corretamente - às alternativas concretas que lhes são apresentadas a cada momento pelas possibilidades do desenvolvimento social. Nisso, portanto, já está implicitamente contido o valor. (LUKÁCS, 2013, p. 122). 
Toda resposta que um indivíduo dá aos problemas que lhe são apresentados busca atender a fins e necessidades definidas pelas circunstâncias postas, objetivando-se em um valor, pois sua ação estará situada entre os polos positivos e negativos, tendendo mais a um do que a outro, diante daquilo que está posto. Ele resigna-se ao estado de coisas ou rejeita-o, acata-o ou desacata-o, repele-o ou aceita-o. Não estamos tentando simplificar para dois tipos de respostas-padrão que os seres humanos dão quando confrontados por dilemas, porque entre elas existem inúmeras mediações e variações, mas é necessário deixar claro que, por trás dessas variações e mediações, sempre encontraremos algum juízo de valor. A volubilidade das posições humanas diante das causalidades dadas não é fruto apenas das circunstâncias legadas pelos indivíduos, pela objetividade social posta, mas também pela própria subjetividade dos indivíduos, conforme problematiza Lukács (2013).

A subjetividade, portanto, é sujeito e objeto. É sujeito porque se autotransforma, é objeto porque é também alvo dos pores secundários de outros indivíduos. Ademais, há uma relação de reciprocidade entre a objetividade social e a subjetividade individual nas posições tomadas pelos seres humanos nas distintas épocas, sociedades e os seus problemas enfrentados. A subjetividade em interação permanente com a objetividade social produz as sínteses causais históricas, os resultados. Nesse sentido, é correto dizer que há uma articulação entre causalidade e teleologia, mesmo na alçada própria de práxis sociais tal qual a política, em que o objeto de intervenção do sujeito é também subjetivo. Como vimos, quando o indivíduo põe teleologicamente, ou seja, de maneira consciente, um conjunto de cadeias causais, por natureza inconscientes, o paradeiro desse pôr entrará na súmula causal da história em curso, pois, ao ser objetivado, ele foge do controle de seu postador. Na política, Maquiavel (2005) dá-nos uma demonstração disso por sua teoria política da virtu e fortuna. Quando discutindo os grandes feitos de alguns ilustres soberanos, avaliou se tais feitos eram resultado do valor ou da boa sorte. E, nesse sentido, assevera que, sem "[...] essa oportunidade, seus valores não teriam sido aproveitados; sem estes, a oportunidade teria sido vã." (MAQUIAVEL, 2005, p. 50). Nessa passagem, pelo menos, fica ilustrada a preocupação do autor não apenas com as virtudes do príncipe, mas com as condições dadas pelos vários fatores em relação.

No trabalho, em seu sentido originário, dos pores primários, está presente a finalidade em todas as etapas de sua execução. Essa finalidade não é só uma finalidade individual, mas antes uma finalidade imersa num contínuo processo de socialização. No decorrer do desenvolvimento societário (desenvolvimento que afirmamos não é no sentido evolutivo), podemos observar que as finalidades dos processos de trabalho começam a entrelaçar-se cada vez mais com as necessidades sociais, com o surgimento dos pores secundários que objetivam fazer com que outros indivíduos realizem pores concretos. Dessa forma, podemos afirmar que, embora os indivíduos sempre tenham e orientem suas ações através de pores teleológicos singulares, esses pores e sua contínua socialização tendem a conformar interesses sociais, de partes, grupos, castas, classes ou qualquer tipo de diferentes estratificações sociais possíveis. Não é plausível que pores secundários incidam sobre os homens se não existir uma heterogeneidade entre eles, uma diferenciação, uma divisão de qualquer natureza.

Entendemos que a política, cuja base origina-se na diferença e na desigualdade (castas, classes, povos, gênero) entre os seres humanos, aliena-se e estranha-se entre eles, é passível de superação à medida que se superem as bases nas quais se sustentam. Esta é, aliás, a tese da ontonegatividade da política de José Chasin (2000). A política, sob esse enfoque, constitui uma práxis que, por processos extremamente complexos e contraditórios, promove a própria desumanização, haja vista que atrofia as possibilidades de desenvolvimento do ser social ao reiterar as relações de dominação de classe. A conquista do poder político pelos trabalhadores no contexto de uma sociedade de classes, assim, precisa ser concebida à luz das reflexões de Marx (2009), nos escritos de Para a Questão Judaica: como meio importante, mas insuficiente para dar concretude à ideia de emancipação humana. Para Marx (2009, p. 71-72, grifos do autor), "[...] só quando o homem reconheceu e organizou as suas forces propres (forças próprias) como forças sociais e, portanto, não separa mais de si a força social na figura da força política - [é] só então [que] está consumada a emancipação humana."

Se a desigualdade de classe, racial/étnica, de gênero, religiosa, ou qualquer outra é possível, ela sempre tende a possuir mediações que levam em última instância à finalidade de que outros indivíduos realizem determinados pores concretos. Nesse sentido, Lukács (2013, p. 90-91) afirma que

[...] é evidente que, em qualquer pôr da causalidade, em que o fim imediatamente posto consiste na transformação da consciência ponente de homens, o interesse social, que está sempre contido em qualquer pôr do fim - e obviamente também naquela do simples trabalho - termina, inevitavelmente, por influir no pôr das cadeias causais necessárias para a sua realização.

Ainda que um conjunto muito variado de interesses deva ser considerado, o autor não hesita em afirmar o papel decisivo que a inserção de classe dos sujeitos exerce nos rumos de suas ações, pois, "[...] uma vez surgidas as sociedades de classes, qualquer questão pode ser resolvida em direções diversas: depende do ponto 
de vista de classe a partir do qual se busca a resposta para o dilema." (LUKÁCS, 2013, p. 152). O ponto de vista de classe, que assume papel decisivo na resolução dos problemas, pode ser analisado em diversos elementos: a ideologia, a política, a ciência, a arte, etc. Os atos valorativos advindos das ações humanas correspondem ao útil, de acordo com os interesses sociais objetivamente fixados no interior dos projetos coletivos, que, no caso das classes, na própria correlação de forças entre elas e como uma determinada ação contribui para a defesa dos interesses de sua classe. Lukács (2013, p. 126) também afirma que

[...] há valores sociais que requerem um aparato institucional que, por certo, podem assumir formas muito variadas a fim de realizar-se socialmente (direito, Estado, religião etc.) e há casos em que as objetivações do espelhamento da realidade se tornam portadoras de valores, fatores que induzem a pôr valores.

A política, assim, configura uma práxis puramente social consubstanciada e concretizada a partir de um conjunto de valores originados no contexto da luta de classes. O Estado, como órgão de dominação de uma classe pela outra, é a raiz e a síntese dos valores políticos em confronto que se materializam no solo mesmo da história, o que reitera nosso argumento inicial sobre a impossibilidade de pensar a política a partir de um critério universal. O ser social, nos termos da tradição teórica a que nos servimos, não é um ser político por natureza, e tampouco está o seu desenvolvimento condicionado à sua capacidade de qualificar ou aperfeiçoar esse pôr teleológico, haja vista que autoimplicado na dinâmica e na estrutura da ordem do capital - forma mais desenvolvida do ser que engendra a própria política.

Em tempos em que se acirram os debates em torno da política no contexto da realidade brasileira, é importante que sejam apontados seus limites, considerando-se que comumente os discursos valorizadores de uma certa ética na política prometem elevá-la a um status com a potência de solucionar todos os males que nos afligem. Contudo, esses discursos, desprovidos de ações que incidam concretamente na realidade de maneira a provocar nela transformações aspiradas pelo cidadão comum do povo, ainda que no âmbito da democracia burguesa, acabam por configurar o mais rasteiro politicismo. De todo modo, tudo isso serve para confirmar o caráter ontonegativo da política e os limites ontológicos a que ela está submetida, pois, por mais intensas que sejam as transformações que dela podem derivar, estas estarão circunscritas aos processos de manutenção da sociedade de classes. Isso porque, de acordo com Marx (2003), “[...] [o] intelecto político é político exatamente à medida em que pensa dentro dos limites da política. Quanto mais agudo ele é, quanto mais vivo, tanto menos é capaz de compreender os males sociais.".

\section{Considerações Finais}

Tanto em Marx quanto em Lukács não é possível identificar uma teoria da política ou uma teoria do Estado, ainda que suas produções teóricas tenham uma dimensão política indiscutível. A despeito disso, as reflexões trazidas por esses autores sobre o caráter ontológico do trabalho e, aí, as relações entre teleologia e causalidades permitem pensar a política como práxis social que implica a projeção do futuro a partir das condições concretas do presente, caracterizadas por diferenças e desigualdades entre pessoas, grupos e classes sociais que dão conformação a determinados projetos societários.

Os processos políticos revolucionários implicam necessariamente ideias críticas ou revolucionárias sobre a objetividade social e, ao mesmo tempo, exigem ações revolucionárias que sejam capazes de dar materialidade àquelas ideias. Fazer política requer, portanto, conhecimento da realidade - sua apreensão do ponto de vista ontológico - sem o que ela se torna um mero voluntarismo ou um politicismo sem potência alguma de transformação. Subjetividade e objetividade, aqui, encontram-se autoimplicadas, e, sem isso, processos sociais inovadores não ganham consecução. Tal pressuposto corrobora o pensamento marxiano que rejeita a ideia de existência de um destino humano previamente traçado - uma sociedade comunista - tendo em conta que a história humana constrói-se a partir de ações concretas consubstanciadas na tradução ideal das causalidades que estão em movimento na realidade social.

Já que o ser social está em permanente desenvolvimento, todos os complexos que o constituem precisam ser situados na história. Assim, não é possível falarmos em política de forma geral e abstrata, posto que sua forma e conteúdo precisam ser compreendidos no processo mesmo da sociabilidade humana que os engendra. No rastro dos nossos interlocutores (Marx e Lukács), entende-se que a necessidade histórica dos trabalhadores impõe pensar a política como mediação para a construção de uma sociabilidade que não tenha como fundamento a propriedade privada e a exploração de classe. Tal perspectiva pressupõe a supressão da própria política e não a sua socialização ou aperfeiçoamento. Essa discussão, contudo, merece ainda muito mais atenção, e o confronto das ideias é bastante salutar. Trata-se, portanto, de um longo debate. 


\section{Referências}

CHASIN, J. A determinação ontonegativa da politicidade. Revista Ensaios Ad Hominem, Santo André, n. 1, t. III, 2000. Edição especial. HARNECKER, M. Estratégia e Tática. 2. ed. São Paulo: Expressão Popular, 2012.

LUKÁCS, G. Para uma ontologia do ser social II. São Paulo: Boitempo, 2013.

MAQUIAVEL, N. O Príncipe. São Paulo: Martin Claret, 2005. 189 p. (A obra-prima de cada autor, n. 2). Comentado por Napoleão Bonaparte.

MARX, K. Glosas críticas marginais ao artigo "O Rei da Prússia e a Reforma Social”.

De um prussiano. Tradução de Ivo Tonet. 2003. Disponível em: <https://www.marxists.org/portugues/marx/1844/08/07.htm>. Acesso em: 18 jan. 2017.

O capital: crítica da economia político. Livro I: O processo de produção do capital. São Paulo: Boitempo, 2013.

. Para a questão judaica. São Paulo: Expressão Popular, 2009.

\section{Notas}

1 Obalcão de granito não está dado na pedra, a mesa não está de antemão disposta na madeira, o plástico não está pressuposto no petróleo, da mesma maneira que não há um tijolo contido imanentemente no barro.

2 A ciência, por exemplo, desenvolve-se a partir do trabalho como conhecimento da realidade, a partir de sua experiência prática desenvolve leis generalizadoras, que, ao confrontarem-se com a realidade, produzem novos resultados, novos conhecimentos que suprassumem as leis precedentes. Segundo Lukács (2013, p. 57): "[...] o ponto no qual o trabalho se liga ao surgimento do pensamento científico e ao seu desenvolvimento é, do ponto de vista da ontologia do ser social, exatamente aquele campo por nós designado como investigação dos meios.” Destaca-se, contudo, que o conhecimento, por maior que seja o esforço humano de apreensão da realidade, é sempre relativo (o que não significa relativismo) e aproximativo.

3 É necessário advertir que não se trata, aqui, de fazer uma correlação automática e desprovida de mediações entre trabalho e política, pois, como se depreende do pensamento de Lukács (2013), é preciso levar em conta as especificidades de todo e qualquer complexo secundário que se desenvolve a partir da base material do trabalho. Nessa direção, compreender a gênese é imprescindível e facilita o processo de apreensão dos processos ulteriores do desenvolvimento do ser.

4 Afirma Lukács (2013, p. 122) que "[...] [todo] valor autêntico, é, pois, momento importante no complexo fundamental do ser social que nós denominamos como práxis. O ser social se preserva como substância no processo de reprodução; no entanto, este último é um complexo e uma síntese dos atos teleológicos que são de fato inseparáveis da aceitação ou da rejeição de um valor. Desse modo, em todo pôr prático é intencionado - positiva ou negativamente - um valor, o que poderia produzir aparência de que os valores nada mais são do que sínteses sociais de tais atos. $\mathrm{O}$ que é correto nisso é que os valores não poderiam adquirir uma relevância ontológica na sociedade se não se tornassem objetos de tais pores."

5 Isso difere da matéria natural que também possui legalidades próprias, mas não vontades e nem convicções, pois caso seu espelhamento estiver correto, o campo de possibilidades de que ela destoe daquilo que estava indicado a mover-se é significativamente menor.

\section{Jaime Hillesheim}

jaimehil@yahoo.com.br

Doutorado em Serviço Social pelo Programa de Pós-Graduação em Serviço Social da Universidade Federal de Santa Catarina (UFSC)

Professor do Departamento de Serviço Social da Universidade Federal de Santa Catarina (UFSC)

\section{Giovanny Simon Machado}

listasme@gmail.com

Mestre pelo Programa de Pós-Graduação em Serviço Social da Universidade Federal de Santa Catarina (UFSC)

\section{UFSC}

Campus Universitário Reitor João David Ferreira Lima

Bairro Trindade

Florianópolis - Santa Catarina - Brasil

CEP: 88.040-970 